
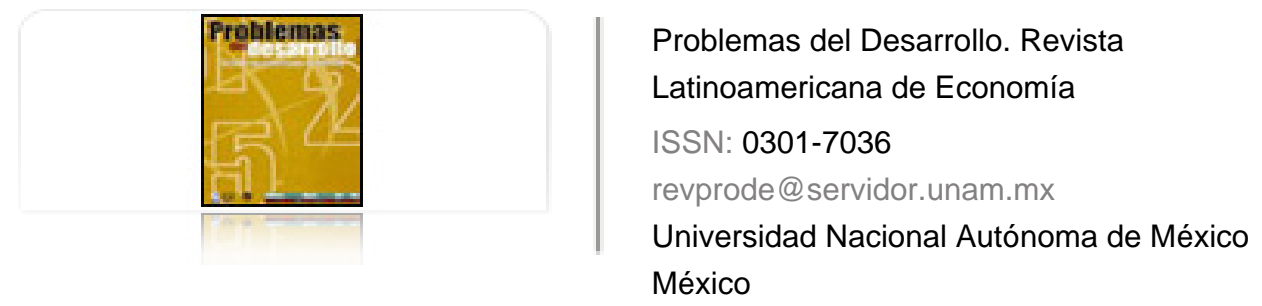

Guillén Romo, Héctor

Integracion monetaria, crisis y austeridad en Europa

Problemas del Desarrollo. Revista Latinoamericana de Economía, vol. 42, núm. 165, abril-junio, 2011, pp. 113-140

Universidad Nacional Autónoma de México

Distrito Federal, México

Disponible en: http://www.redalyc.org/articulo.oa?id=11819780006

Cómo citar el artículo

- Número completo

- Más información del artículo

Página de la revista en redalyc.org

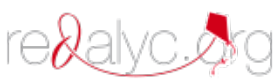

Sistema de Información Científica

Red de Revistas Científicas de América Latina, el Caribe, España y Portugal Proyecto académico sin fines de lucro, desarrollado bajo la iniciativa de acceso abierto 


\title{
INTEGRACIÓN MONETARIA, CRISIS Y AUSTERIDAD EN EUROPA
}

\section{Héctor Guillén Romo*}

Fecha de recepción: 8 de noviembre de 2010. Fecha de aceptación: 9 de marzo de 2011.

\begin{abstract}
RESUMEN
Partiendo de un análisis de la construcción neoliberal de la integración monetaria europea se analizan la crisis económica griega y las políticas de austeridad de corte hayekiano que se están utilizando para enfrentarla. Tras caracterizar teóricamente dichas políticas, se analiza cómo su generalización en Europa contribuye a profundizar la crisis europea comprometiendo la reactivación de la economía mundial. No obstante, la causa de la crisis es la pérdida de soberanía monetaria de cada país y el financiamiento del Estado se sustenta a través de los inversionistas financieros bancarios y no bancarios.
\end{abstract}

Palabras clave: integración monetaria, crisis europea, políticas de austeridad, Hayek.

\section{MONETARY INTEGRATION, CRISIS AND AUSTERITY IN EUROPE}

\begin{abstract}
Starting with an analysis of the neoliberal construction of European monetary integration, the Greek economic crisis and the Hayekian-style austerity policies being used to deal with it are analyzed. After theoretically characterizing these policies, the paper analyzes how their generalization in Europe is helping to deepen the European crisis and jeopardizing the recovery of the world economy. Nevertheless, the reason of the crisis is the loss of monetary sovereignty of every country and the financing of the State is sustained across the financial bank and not bank investors.
\end{abstract}

Key words: monetary integration, European crisis, austerity policies, Hayek.

* Docente-Investigador, Departamento de Economía y Gestión de la Universidad de París 8. Correo electrónico: h.guillen@wanadoo.fr 


\section{INTÉGRATION MONÉTAIRE, CRISE ET AUSTÉRITÉ EN EUROPE \\ Résumé}

En partant d'une analyse de la construction néolibérale de l'intégration monétaire européenne, sont analysées la crise économique grecque et les politiques d'austérité de tendance hayekienne qui ont été mises en œuvre pour la combattre. Après une caractérisation théorique de ces politiques, il est analysé comment leur généralisation en Europe contribue à aggraver la crise européenne compromettant ainsi la réactivation de l'économie mondiale. Cependant, la cause de la crise est la perte de souveraineté monétaire de chaque pays et le financement de l'État est alimenté par le biais des investisseurs financiers banquiers et non banquiers.

Mots clés : intégration monétaire, crise européenne, politiques d'austérité, Hayek.

\section{INTEGRAÇÃO MONETÁRIA, CRISE E AUSTERIDADE NA EUROPA \\ Resumo}

Partindo de uma análise da construção neoliberal da integração monetária européia, se analisam a crise econômica grega e as políticas de austeridade de corte hayekiano que se estão utilizando para enfrentá-la. Depois de caracterizar teoricamente ditas políticas, se analisa como sua generalização na Europa contribui a aprofundar a crise européia comprometendo a reativação da economia mundial. Não obstante, a causa da crise é a perda de soberania monetária de cada país e o financiamento do Estado se sustenta através dos investidores financeiros bancários e não bancários.

Palavras-chave: Integração monetária, Crise européia, Políticas de austeridade, Hayek.

货币一体化，欧洲的危机与财政紧缩

赫克托耳・吉延・罗默

概要

从对欧洲货币一体化的新自由主义构造的分析出发, 对希腊的经济危机及 正在被运用以应对危机的哈耶克主义财政紧缩政策进行分析。在理论性地 指出这些政策的特点之后，分析了这些政策在欧洲的普及如何导致危机的 深化同时危及世界经济的复苏。然而，危机的起因是各国货币主权的丧失 而国家财政来源则由银行或非银行的经融投资所支撑。

关键词: 货币一体化, 欧洲危机, 财政紧缩政策, 哈耶克 


\section{UNA CONSTRUCCIÓN NEOLIBERAL DE LA EUROPA MONETARIA}

El Tratado de Maastricht (Kauffmann, 1997) firmado el 7 de febrero de 1992 tuvo por finalidad crear en Europa una unión monetaria que desembocara en un plazo dado en una moneda única. La principal innovación institucional del Tratado será la creación de un Banco Central Europeo (BCE) cuya misión central será la definición e implementación de la política monetaria de la Unión Monetaria. El proceso de integración monetaria siguió tres etapas. La primera comenzó en 1990 antes de la redacción del Tratado de Maastricht con la liberalización completa de los movimientos de capitales y la terminación del mercado único. En esta etapa se reforzó también la coordinación y la vigilancia multilateral de las políticas económicas. El paso a la segunda etapa se efectuó el primero de enero de 1994 cuando entra en función el Instituto Monetario Europeo (embrión del futuro banco central europeo) y los países que aspiran a la unión se someten a dos tipos de medidas nuevas. Las primeras se refieren a la independencia de los bancos centrales y al financiamiento de los déficits públicos. Los institutos de emisión de los Estados que desean participar en la unión monetaria europea deben volverse totalmente independientes de los poderes políticos nacionales. Paralelamente a los bancos centrales se les prohíbe financiar directamente la administración y las empresas públicas con la excepción de los bancos comerciales. Para financiarse, los Estados, supuestamente despilfarradores, deben encontrar prestamistas en los mercados financieros, por hipótesis eficientes y omniscientes. ${ }^{1}$ Se trata de una auténtica privatización de las finanzas públicas que obliga a los Estados a endeudarse con los bancos comerciales en las mismas condiciones que los agentes privados para financiar sus gastos (Parguez, 2002: 4). Las segundas medidas se refieren a la convergencia económica. Los Estados se esforzaron por respetar diferentes criterios de convergencia que jugaron un papel decisivo para el paso a la tercera etapa de la unión que se inició el primero de enero de 1999. Los criterios de convergencia fueron cinco:1) las tasas de inflación de los países candidatos no debían superar en 1.5\% las de los tres países con menor inflación; 2) el déficit presupuestal no debería superar

1 En estas condiciones se estaba instaurando una "represión monetaria" que acompañaba a la "liberalización financiera", una situación completamente opuesta a la que se instauró tras la crisis de los treinta con una "represión financiera" (restricciones drásticas a la libertad de acción de la finanza) acompañada de una "liberación monetaria” (fin del patrón oro) (Askenazy y otros, 2010: 38). 
3\% del рів; ${ }^{2}$ 3) la deuda pública bruta de los Estados no debería exceder 60\% del PIB; ${ }^{3} 4$ ) el margen de fluctuación estrecha de los tipos de cambio dentro del sistema monetario europeo debería ser respetado durante al menos dos ańos sin devaluación ni tensión; 5) las tasas de interés a largo plazo no deberían exceder en más de $2 \%$ el promedio de los tres Estados que hayan tenido los mejores resultados en materia de estabilidad de precios. ${ }^{4} \mathrm{La}$ tercera fase debutó con la

2 Cabe señalar que fueron los alemanes los que más insistieron para que se fijara un techo imperativo a los déficits públicos temiendo embarcarse en una unión monetaria con los países despectivamente denominados del club Med (Grecia, Espańa, Portugal, Italia) considerados laxistas en materia financiera. Con respecto al límite fijado varias preguntas se vuelven pertinentes: ¿Por qué un umbral máximo de 3\% fue adoptado? ¿Por qué no más? ¿Por qué una sola definición de déficit presupuestal? ¿Por qué no se distinguió la parte del déficit imputable únicamente a la coyuntura (déficit coyuntural) de la resultante de decisiones discrecionales de los gobiernos (déficit estructural)? ¿Por qué no haber fijado al déficit estructural un valor máximo de 3\% y al déficit coyuntural un valor más importante de 6\%? (Bousseyrol, 2009: 141).

3 A decir verdad, las cifras de 3\% para el déficit y $60 \%$ para la deuda fueron escogidas apoyándose en una ecuación que pone en relación la dinámica de la deuda pública con la tasa de crecimiento de la economía y el nivel de la tasa de interés. Cuando se fijaron los criterios de convergencia el crecimiento era fuerte y las tasas de interés reales débiles. Desde entonces las condiciones han cambiado pero las cifras se volvieron un tabú. No obstante, cualesquiera que sea el valor máximo del déficit o de la deuda, la creación de una norma institucional de medida cumple una misión política importante: demostrar de manera cifrada que existe un umbral más allá del cual la deuda o el déficit no es soportable. Más allá de este límite, las condiciones de un crecimiento sano estarían comprometidas y el orden social se pondría en peligro (Bousseyrol, 2009: 60; Dévoluy: 77).

4 Cabe señalar que los criterios escogidos no fueron criterios económicos sino criterios de política económica pública (déficits, inflación, tasas de interés): se trataba de incitar los Estados a transformar la realidad económica para acercarla al funcionamiento efectivo de "una zona monetaria óptima”. A este respecto recordemos que desde los años sesenta Mundell, a quien numerosos observadores consideran como uno de los "padres" del euro, planteó una pregunta nueva y fundamental: ¿̨ajo qué circunstancias es ventajoso que varios países renuncien a la independencia de su política monetaria e incluso a su soberanía monetaria a favor de una unión monetaria? Según Mundell la moneda común presupone una fuerte integración comercial, un nivel elevado de especialización productiva, una gran movilidad de los factores de producción (capital pero también trabajo), una gran flexibilidad de precios y salarios, mecanismos de transferencia presupuestales significativos, una simultaneidad de los ciclos económicos y finalmente preferencias comunes. Aunque Europa no satisfacía todos los criterios establecidos, particularmente la alta movilidad de mano de obra y mecanismos de transferencia presupuestales significativos, Mundell ha sido siempre un ardiente defensor del euro. De hecho no existe ni existirá probablemente nunca una zona que responda a tales criterios: éstos describen más los efectos de una moneda común ya existente que condiciones realistas para su creación (Mundell: 1961; Wallace: 2007). 
fijación irrevocable de los tipos de cambio de los países aspirantes a la unión. El BCE sustituyó al Instituto Monetario Europeo (los bancos centrales nacionales se volvieron antenas locales del BCE) y el euro se volvió jurídicamente la moneda única de la Unión. Sin embargo, las monedas nacionales continuaron circulando hasta 2002 tanto para permitir la introducción progresiva de nuevos billetes y piezas, como para que el público se acostumbrara al euro. Por otro lado, los Estados miembros se comprometieron en 1997 a respetar el Pacto de Estabilidad y Crecimiento que perenniza y refuerza los criterios de Maastricht relativos a las finanzas públicas.

Dichos criterios muestran la orientación neoliberal de la Unión Monetaria imponiendo una serie de restricciones exorbitantes y esterilizantes (Bliek y Parguez, 2006: 98-102).

La soberanía monetaria del Estado es abolida por primera vez en la historia de la economía moderna. La moneda se vuelve supranacional y es administrada por una banca soberana totalmente independiente de cualquier poder político. ${ }^{5}$ El BCE es mucho más independiente que la Federal Reserve System (FED) y el Banco de Inglaterra e incluso que el Banco de Francia cuando era privado. En Estados Unidos la FED no tiene un estatuto de componente autónomo del gobierno federal. Estatutariamente y en la práctica la FED tiene objetivos más amplios que el FED. Además, está obligada a rendir cuentas al Congreso. En el caso de Inglaterra, aunque el banco central es independiente del gobierno, lo es menos que el FED con respecto a los miembros de la Unión.

La inflación es considerada como el peligro principal. La independencia total del FED tiene por objetivo lograr el cumplimiento de su única misión: la estabilidad cuasi absoluta de los precios. El FED dispone del control absoluto de la política monetaria para alcanzar una inflación que tiene como límite superior $2 \%$. Más allá se considera que la economía está sobrecalentada. Esto significa fijar permanentemente su tasa de interés de base a una altura suficientemente elevada para permitir ajustar la demanda agregada a un nivel compatible con el equilibrio general. ${ }^{6}$

5 Se cumple el ideal neoliberal de Hayek de disponer de "una autoridad monetaria independiente, totalmente protegida de presiones políticas y libre de decidir de los medios que hay que implementar para alcanzar los objetivos que se le han asignado" ( Hayek, 1994: 332).

6 Desde una perspectiva Wicselliana se considera que en el largo plazo el crecimiento económico está determinado por factores de oferta (productividad del trabajo, crecimiento demográfico, acumulación de capital dependiente del ahorro). La economía sólo se alejaría del sendero natural de crecimiento donde reinaría la estabilidad absoluta de precios debido a las variaciones de la demanda global. La demanda global variaría en función de choques provocados por 
El BCE está además encargado de implementar la política de cambio de la moneda europea con respecto a otras monedas. Aunque las orientaciones de la política de cambio son definidas por el Consejo Europeo, se estipula que esta política no puede contrariar el objetivo prioritario de estabilidad de precios asignado al BCE. Así, la política monetaria, por derecho, y la política de cambio, en los hechos, son determinadas por el вСЕ.

La Unión Económica y Monetaria es el resultado de un proceso histórico que se inició a finales de los años veinte. Su objetivo fue explícitamente el surgimiento de un Nuevo Orden Europeo que realizara una economía de mercado perfecta, fundamentada en los principios de la escuela austriaca (Menger, Mises, Hayek). ${ }^{7}$ Todo se implementó para organizar el debilitamiento del Estado, fuente de todos los males, lo que permitiría superar todos los obstáculos al libre juego del mercado. En estas condiciones "no debe sorprender que los diseñadores de la unión monetaria hayan hecho todo lo posible para proscribir cualquier política de inspiración keynesiana" (Bliek y Parguez, 2006: 101).

El Congreso de los Estados Unidos nunca ha aceptado y ni siquiera considerado votar una enmienda a la Constitución para imponer el equilibrio

una baja de ahorro o por una política presupuestal expansionista. La misión del banco central consiste entonces en neutralizar la demanda restringiéndola suficientemente para forzar la convergencia de la economía al sendero de equilibrio natural. La idea es que a corto plazo los choques de demanda provocados por un alza de salarios o un déficit presupuestal perturbarían la economía en tanto que a largo plazo sólo los factores de oferta o estructurales como la población, la productividad o el ahorro contarían. Esta teoría según la cual el corto plazo es determinado por la demanda y el largo por la oferta no tiene ningún fundamento sólido. La evidencia empírica ha demostrado que las mismas variables actúan tanto en el corto como en el largo plazo. Se trata de variables de demanda, la más importante siendo el consumo, que empujan la inversión y posteriormente el gasto público (Bliek y Parguez , 2006: 99).

El rechazo del Estado unifica a todos los representantes de la escuela neoliberal austriaca. Para ellos el mercado triunfa siempre. El respeto de los mecanismos de mercado constituiría la única manera de garantizar el mantenimiento del capital necesario para que la sociedad siga existiendo. El mercado siempre tendría razón. Las políticas económicas del Estado son siempre perturbadoras. Los neoliberales austriacos no creen en la legitimidad del Estado. Para ellos la única legitimidad es la soberanía del mercado. Aceptan fácilmente perder los instrumentos de política económica, como el déficit presupuestal o la política monetaria, ya que están convencidos de que son inútiles o nefastos en las manos del Estado. El objetivo fundamental de los neoliberales sería realizar una economía de mercado perfecta integralmente sometida al principio de la competencia. En nombre de dicho principio debería transferirse al sector privado todo lo que puede ser privatizado. 
presupuestal, a pesar de la recomendación de Milton Friedman en este sentido. ${ }^{8}$ Ahora bien, todos los Estados miembros de la Unión Económica y Monetaria se comprometieron a respetar las reglas del Pacto de Estabilidad y Crecimiento (elaborado en la cumbre de Dublín en 1996 y confirmado con el Tratado de Amsterdam en 1997). Según dicho pacto: 1) El déficit presupuestal deberá limitarse a 3\% del PIB, porcentaje definido, como ya señalamos, de manera totalmente arbitraria;' 2) A largo plazo en el sendero de crecimiento natural, el saldo presupuestal debe ser cuando menos nulo y de preferencia presentar un excedente para compensar la insuficiencia del ahorro privado; 3) La deuda pública bruta no debe nunca superar 60\% del PIB. Según el marco teórico que inspira el Pacto una deuda pública demasiado importante sería el origen de efectos de desplazamiento: las necesidades de préstamo del Estado privaría a las empresas de recursos financieros y tendería a aumentar las tasas de interés. ${ }^{10}$

8 Recordemos que Milton Friedman propuso una enmienda constitucional para obligar al congreso de los Estados Unidos a equilibrar el presupuesto de la nación (Friedman, 1971). Como lo demuestra James Galbraith, el equilibrio presupuestal en los Estados Unidos fue el primer pilar conservador que se desplomó constituyendo "un sueño imposible de realizar" (2009: 85-104).

9 No obstante, el umbral de 3\% del piB puede ser superado si un país conoce una recesión de su PIB anual de más de $2 \%$. Si la baja del PIB está comprendida entre $-2 \%$ y $-0.75 \%$, el Consejo de ministros de la Unión evalúa la situación del país y decide sobre la oportunidad de una sanción o de una tolerancia excepcional. En caso de un desbordamiento no autorizado el país se expone a multas que se vuelven definitivas si el gobierno no toma las medidas necesarias para conformarse al pacto de estabilidad.

10 El efecto de desplazamiento presentado por los monetaristas en los ańos sesenta, tiene su origen en lo que se conoce como el punto de vista del Tesoro desarrollado en los años veinte por el Ministro de Hacienda inglés (y por el economista R. Hawthrey). Tal punto de vista excluye cualquier política de lucha contra el desempleo gracias a un crecimiento del gasto público. La idea es que la necesidad de fondos de un Estado que gasta más que sus ingresos fiscales provoca un aumento de sus necesidades de capital y en consecuencia un aumento de la tasa de interés. La inversión de las empresas se reducirá en virtud del aumento del costo del dinero. Se habla entonces de "efecto de suplantación": los gastos públicos excesivos y considerados $a$ priori como improductivos o menos productivos, suplantan los gastos privados considerados potencialmente más benéficos. En los años setenta "los nuevos clásicos" pretendieron incluso que el déficit público no tendría ningún efecto positivo a corto plazo debido a "las anticipaciones racionales" de los agentes privados. Estos últimos saben que el déficit no tendrá ningún efecto sobre la riqueza nacional y que la generosidad actual del Estado desembocará en el futuro en impuestos y cotizaciones suplementarias. Así, desde el anuncio de la reactivación presupuestal, los agentes privados reducirán su gasto para hacer frente a los futuros impuestos. El desplazamiento del gasto privado por el gasto público es instantáneo. Sin embargo, la hipótesis de un desplazamiento del gasto privado por el gasto público no se verifica 
La contrapartida de la deuda pública en términos de inversiones colectivas o sociales no es tomada en cuenta. Vale la pena hacer notar que aunque se anexó el término crecimiento al de estabilidad, el Pacto no tiene ningún objetivo de crecimiento ni de pleno empleo. Se trata simplemente de imponer a los participantes en la zona euro la misma política presupuestal ante la imposibilidad de que los Estados de la Unión transfieran la política presupuestal a una autoridad supranacional. ${ }^{11}$

El Pacto restringe las posibilidades de que los estabilizadores automáticos ${ }^{12}$ puedan jugar un papel anticíclico con el riesgo de imponer a los países en recesión políticas presupuestales demasiado rigurosas. Además, la limitación de los márgenes de maniobra presupuestales de los países en dificultad refuerzan la incitación peligrosa al dumping fiscal y social: salarios más bajos, una protección social menos generalizada y menos costosa, y una fiscalidad más ventajosa para las ganancias. Todos estos factores pueden constituir una incitación a la relocalización intra-europea de las empresas en beneficio de los países que adoptan una lógica de lo menos social y fiscal posible, favoreciendo el alineamiento hacia abajo de los niveles de vida y de trabajo de los asalariados. Dicho de otra manera, los Estados privados de instrumentos de reacción frente a un mal resultado con respecto a sus vecinos deberán dejar jugar más los mecanismos de mercado. La restauración de la competitividad exigirá la flexibilidad de la mano de obra, la baja de los costos salariales y de las cargas fiscales. La disminución de la carga fiscal,

empíricamente. La reactivación monetaria se realiza normalmente en una situación en la que las familias y las empresas reducen sus gastos: no hay entonces penuria de ahorro sino de inversiones. Pidiendo prestado los fondos que los agentes no quieren invertir, el Estado no los priva de nada. Sólo toma el relevo. El gasto público no substituye al gasto privado, sólo lo complementa de dos maneras: por un lado asegurando la producción de bienes públicos e infraestructuras sin las cuales ninguna actividad privada prosperaría. Por otro lado, reactivando los intercambios cuando se han paralizado (Généreux, 2002).

11 Para Alain Parguez, la identidad de las políticas presupuestales requiere que todos los Estados tengan a corto y a largo plazo el mismo déficit a precios constantes en proporción de su ingreso real; que el crecimiento a corto y largo plazo del gasto público sea el mismo a precios constantes; que acontezca lo mismo para los impuestos; que la estructura de gastos e impuestos sea la misma; que jamás se tome en cuenta para un Estado la situación particular de su economía sino sólo la situación global de la Unión, que toda infracción a las reglas antes mencionadas sea instantáneamente sancionada por una autoridad supranacional soberana (Parguez, 2002: 2-3).

12 En periodo de recesión, espontáneamente, los impuestos tienden a reducirse (baja de ingresos) y los gastos públicos a aumentar (aumento del desempleo) e inversamente en periodo de auge. Dichas evoluciones del presupuesto contribuyen a estabilizar la actividad económica. Por lo general, los estabilizadores automáticos si bien atenúan la baja del producto no bastan para reactivar la economía. 
bajo una restricción de equilibrio presupuestal, supone una disminución del gasto público y por lo tanto un importante retiro del Estado (Généreux, 1999: 346).

En estas condiciones, la política económica deja de existir siendo sustituida por una gestión que impone a pesar de todos los obstáculos las normas europeas arbitrarias. Como a nivel europeo, toda política presupuestal fue excluida por principio, ${ }^{13}$ cualquier posibilidad de acción es excluida. En efecto, los partidarios de la Unión Monetaria no querían encontrar a nivel europeo un poder político que habían buscado exorcizar a nivel nacional. Es decir, no estaban dispuestos a aceptar alguna forma de gobierno económico europeo que diera órdenes a los diferentes gobiernos nacionales (Bliek y Parguez, 2006: 101-102).

Reduciendo la demanda global, el respeto intransigente de las normas del Pacto de Estabilidad y Crecimiento termina por obligar a los sindicatos y de una manera general a los asalariados a aceptar las sacrosantas "reformas estructurales indispensables". El razonamiento similar al desarrollado por Hayek a fines de los treinta es muy simple. Mientras más reduce el Estado la demanda global más aumentará el desempleo efectivo, para una situación dada de rigideces del trabajo, por encima de su nivel natural. Llegará un momento en que el aumento del desempleo será tal que impondrá una reducción de los salarios reales y así la deflación salarial terminará por enseñarles a los asalariados la dura lección de la austeridad. Se verán obligados a renunciar a una protección social que sólo agravaría sus males. En estas condiciones, el proceso de deflación permitiría retomar el camino de la prosperidad.

De lo anterior se deduce que toda la construcción de las instituciones monetarias europeas - desde los criterios de convergencia hasta los objetivos estatutarios del $\mathrm{BCE}-$ tienden a hacer de Europa la defensora de una dolorosa ortodoxia presupuestal. La visión dominante actualmente en Bruselas es una visión neoliberal que trata de adaptar las sociedades europeas a las exigencias de mundialización. La construcción europea se ha convertido en una palanca poderosa para imponer las reformas neoliberales.

13 La Unión Europea no dispone de un presupuesto federal europeo comparable al presupuesto federal de los Estados Unidos (24\% del PIB). El presupuesto europeo con un tope máximo de $1.2 \%$ del pIB resulta irrisorio con respecto al de los Estados nacionales. En estas condiciones se puede considerar que la zona euro no es una auténtica unión monetaria al estar desprovista de federalismo presupuestal, uno de los elementos claves de una unión monetaria óptima. Eichengreen subrayó los límites de la analogía entre la unificación monetaria en los Estados Unidos y la trayectoria seguida en Europa. En Estados Unidos la unificación monetaria se inscribió en un proceso político más amplio de unificación presupuestal en la que los Estados de alguna manera son compensados de la pérdida de su autonomía monetaria gracias a su pertenencia a un conjunto presupuestal unificado que permite hacer jugar la solidaridad sistémica gracias a las transferencias de ingreso (D’Arvisenet, 2011: 9; Eichengreen, 1990). 
Así, en tiempos de tranquilidad económica, la Unión Económica y Monetaria funciona aunque la zona euro no sea óptima desde el punto de su coherencia interna. El BCE y el PEC permiten borrar superficialmente la heterogeneidad de las estructuras económicas, políticas y sociales. Pero cuando la tormenta llega, las restricciones que pesan sobre la Unión se endurecen. Esto lleva a la austeridad presupuestal impuesta a los Estados y a la acentuación del rigor salarial infligido a los asalariados, lo que genera una pérdida de confianza en la Unión.

\section{LA CRISIS EUROPEA}

La economía mundial atravesó desde 2007 una serie de crisis cuya secuencia en tres actos es ahora bien conocida: el episodio de los subprimes desencadenado por el estallido de la burbuja inmobiliaria americana desembocó en una crisis financiera y bancaria sistémica (primer acto) que se transformó debido al impacto macroeconóomico sobre las empresas (debilidad de la inversión) y las familias (aumento del desempleo y endeudamiento privado) en una crisis real de escala planetaria (segundo acto). Cuando a inicios de 2010 parecía que la tempestad se había alejado, el deterioro de las finanzas públicas y el endeudamiento público de los Estados, como consecuencia de la recesión y de los planes de reactivación masivos, condujo a una crisis de las deudas soberanas en la zona euro (tercer acto). En efecto, el apoyo a los bancos y la amplitud de los planes de reactivación tras la crisis de los subprimes se tradujeron en un alza de la relación deuda pública/ PIB que alcanzó un nivel tal que suscitaron dudas entre los financieros internacionales en cuanto a la continuación de tales políticas a mediano y largo plazo. El nivel de las deudas públicas alcanzó 80\% del piB en el Reino Unido, 85\% en la zona euro, 95\% en los Estados Unidos y 195\% en Japón (Sterdyniak, 2010). Se había operado un traspaso directo del riesgo privado a un mayor riesgo de la deuda soberana. ${ }^{14}$ Estados Unidos, Reino Unido, Irlanda, España y Grecia se encontraban en primera línea de los países amenazados. De hecho, Grecia fue el

14 Lo acontecido con la deuda pública en Europa no es nuevo. En efecto, los datos sobre la evolución de la deuda pública tras las principales crisis bancarias de posguerra tanto en los países avanzados como en los subdesarrollados muestran en promedio una cuasi duplicación en los tres ańos posteriores a la crisis (incluso sin tomar en cuenta la deuda de las colectividades públicas y la deuda garantizada por el Estado). En estas condiciones se puede considerar que el verdadero legado de las crisis bancarias es un alza del endeudamiento público que supera y excede ampliamente los costos directos de los grandes planes de salvamento (Reinhart, C.M. y Rogoff, KS, 2010: 191-193). 
primer país amenazado, ya que debido a un cambio de gobierno, las autoridades descubrieron y señalaron que los déficits anteriormente declarados habían sido ampliamente subestimados. En estas condiciones, el 20 de octubre de 2009 el nuevo ministro de Hacienda griego anunció que el déficit público no representaría 5\% del pib sino 12.5\% (revisado posteriormente a 13.6\%). Es el inicio de una espiral especulativa alimentada por los CDS (Credit Default Swap $)^{15}$ soberanos adosados a la deuda de un Estado que abren la posibilidad de especular sobre la deuda griega sin poseerla, después de que un banco de inversión americano ayudó al gobierno a sacar de las cuentas públicas una parte significativa de la deuda pública. Por otro lado, desde fines de octubre de 2009 hasta principios de mayo de 2010 los dirigentes europeos, sobre todo los alemanes, ofrecieron un espectáculo asombroso de declaraciones y anuncios contradictorios, mostrando al mundo y particularmente a la comunidad financiera internacional que Europa no tiene un gobierno ni una política económica y presupuestal común y solidaria. ${ }^{16}$ La situación empeoró el 15 de junio de ese mismo año cuando la agencia de notación Moody’s degradó la nota de la deuda pública griega. ${ }^{17}$ Como muchos bancos extranjeros (alemanes, franceses, españoles...) habían adquirido títulos

15 Los Credit Default Swaps son formas de seguro contra el riesgo de impago (si, por ejemplo, la deuda griega no pudiera pagarse), de restructuración (si se prolonga el periodo de reembolso inicialmente previsto) o de moratoria (plazo más largo para pagar la deuda) por parte del deudor. Una aseguradora o un banco garantiza, con un contrato de seguro, al titular de la deuda que esta última le será pagada al plazo estipulado por el monto convenido. El costo de tal seguro es evidentemente función de la probabilidad de que el deudor no cumpla tal y como la aprecia el mercado. Los CDS pueden revenderse en algunos mercados financieros y las fluctuaciones de sus precios de mercado revelan las apreciaciones de los operadores del mercado en torno a la evolución del riesgo vinculado a los créditos que los CDS garantizan. Resulta claro que la existencia de estos CDS permite e incluso favorece los movimientos especulativos. Los especuladores que apostaron sobre el incumplimiento griego compraron masivamente CDS sobre la deuda griega.

16 Los Estados de la zona euro abandonaron sus poderes monetarios pero no fueron capaces de dar el segundo paso transfiriendo una parte de sus poderes presupuestales. La única salida fue entonces imponer una fuerte independencia del banco central y reglas estrictas en materia de finanzas públicas.

17 A este respecto cabe señalar que "La evaluación financiera no es neutral: afecta el objeto medido, compromete y construye el futuro que imagina. Así las agencias de notación financiera contribuyen ampliamente a determinar las tasas de interés en los mercados de obligaciones atribuyendo notas muy subjetivas incluso con una voluntad de alimentar la inestabilidad, fuente de beneficios especulativos. Cuando degradan la nota de un Estado, aumentan la tasa de interés exigida por los actores financieros para adquirir los títulos de la deuda pública de dicho Estado aumentando por lo mismo el riesgo de quiebra que han anunciado" (Askenazy y otros 2010: 22). 
de la deuda griega ${ }^{18}$ sus cursos en bolsa cayeron y la tasa de interés interbancaria sufrió un alza repentina dado que los financieros temían que el incumplimiento griego desencadenara una crisis bancaria y financiera europea e incluso mundial. En este contexto, no es sorprendente que esta situación haya dado la ocasión a los bancos de inversión y a los fondos especulativos anglosajones de especular con el escenario de una crisis griega fuera de control pudiendo conducir a una desagregación de la zona euro. ${ }^{19}$ A través de Grecia, los especuladores percibieron las fallas en la organización de la zona euro: la Unión Europea no dispone de un útil comunitario para evitar el incumplimiento de un Estado (de manera intencional para evitar los efectos del "azar moral") ${ }^{20}$ y tampoco de poder suficiente para detectar a tiempo una evolución macroeconómica nacional susceptible de cuestionar la viabilidad del euro. Desde mediados de 2009 los mercados comenzaron a temer y a especular sobre el incumplimiento de algunos países de la zona euro (Grecia, Irlanda, España, Portugal e Italia denominados "el club de los cinco" $)^{21}$ que debieron progresivamente financiarse a tasas cada vez más elevadas con respecto a otros países de la zona, lo que constituye un buen ejemplo de externalidad financiera. ${ }^{22}$ En abril de 2010 el diferencial con Francia de los títulos a diez años alcanzó 0.5 puntos para Espańa e Italia, 1.4 puntos para Irlanda, 5.3 puntos para Grecia. Esto, sin que ningún país desarrollado hubiera incumplido desde 1945 (Sterdyniak, 2010: 31). Pero los mercados se dieron cuenta de una falla en la organización de la zona euro: en tanto que los gobiernos de los otros países desarrollados pueden siempre ser financiados por su Banco Central, los

18 El 80\% de la deuda griega estaba en manos de bancos europeos (Couderc y Montel-Dumont: 7).

19 Entre los especuladores se encuentra el banco Goldman Sachs que durante largo tiempo asesoró al gobierno griego permitiéndole gracias a su "creatividad contable" mostrar cuentas presentables para su entrada en el euro y posteriormente se encargó de colocar su deuda en los mercados aunque ¡especulando por su lado sobre el incumplimiento griego!

20 Riesgo que asume una persona cuando opera respaldada por una póliza de seguro.

21 Nótese que países como Irlanda y España que habían sido considerados durante mucho tiempo como "buenos alumnos" del pacto con bajos niveles de déficit y de deuda pública, pasaron a formar parte del "club de los cinco" o de la "Europa vulnerable", nueva categoría para designar a los países que suscitan la desconfianza de los mercados financieros.

22 Si un incumplimiento griego o una restructuración podría ser absorbida, su contagio a varios países podría haber desencadenado una crisis bancaria. Así, según el Banco de Pagos Internacionales la exposición bancaria total de Francia y de Alemania con respecto a Grecia, Portugal, Irlanda y España (incluyendo la cartera de deuda directa y la indirecta a través de sus filiales) representa alrededor de $15 \%$ de su Рів. Incluso descuentos limitados sobre las deudas públicas de algunos países podrían poner en peligro al sistema bancario de la zona euro (Bénassy-Quéré y Boone, 2010: 2). 
países de la zona euro renunciaron a esta posibilidad dependiendo totalmente de los mercados para financiar sus déficits. Debido a todo esto y a la tardanza de los países europeos para elaborar un plan de salvamento de Grecia, la especulación se extendió contra los títulos de la deuda pública de los países más frágiles (Portugal, España) o más endeudados de la zona euro (Italia). Privados de la garantía de poder financiarse en el BCE, los países del Sur de Europa se volvieron víctimas de ataques especulativos. Así curiosamente países como Grecia, Portugal y España que a principios de los setenta eran aún dictaduras, se ven ahora sometidos a una nueva forma de dictadura: la dictadura de los mercados financieros que en la mayoría de los casos no son otros que establecimientos financieros instalados en los países miembros de la Unión Europea.

Los gobiernos de la zona euro, acorralados por el temor a la extensión del contagio a todos los mercados de capitales del mundo y ante las presiones de los dirigentes americanos y del FMI, terminaron por hacer frente a sus responsabilidades reaccionando con la amplitud requerida para hacer frente a la crisis sistémica. Se desplegaron medios de intervención de urgencia (60 mil millones de euros) y garantías gubernamentales asociadas ( 440 mil millones de euros) para permitir que una nueva agencia financiera o Fondo de estabilización colecte fondos en los mercados con el propósito de comprar la deuda de los países frágiles. Lo anterior se acompaña de un apoyo inmediatamente operacional del FMI por 250 mil millones de euros. Además, operando un viraje sin precedente respecto a su ortodoxia infalible el BCE acepta comprar obligaciones de Estado a la tasa de interés del mercado para calmar las tensiones en el mercado europeo de obligaciones (el BCE se transformó en un importante tenedor de deuda griega).

En 2010, ante la agravación de la situación, los gobiernos europeos tuvieron que escoger entre dos estrategias (Sterdyniak, 2010: 30-31). La primera defendida por los Estados Unidos y los economistas keynesianos consideraba que el crecimiento estaba aún ausente por lo que había que mantener políticas presupuestales expansionistas. Se consideraba que el crecimiento permitiría colmar el déficit. La deuda pública podría sin problema mantenerse en $90 \%$ o $100 \%$ del pib en la medida en que fuera demandada por los ahorradores y los mercados. Los déficits públicos se reducirían cuando ya no fueran necesarios, es decir, en caso de fuerte baja del ahorro o alza de la inversión. La segunda estrategia, preconizada por las instituciones internacionales, los gobiernos europeos y los economistas neoliberales recomendaba hacer todo lo posible para reducir rápidamente el nivel de la deuda. Una deuda pública superior a $60 \%$ del PIB originaría en un cierto plazo una tensión sobre las tasas de interés frenando el crecimiento. Incitaría más a las familias a ahorrar previendo alzas futuras de impuestos necesarias para la recuperación de las finanzas públicas. Según este 
enfoque neoliberal, los países deberían desde ahora comprometerse con una política restrictiva que aumentara la tasa de ahorro de las familias. Bajo la presión de los mercados, de las agencias de notación, del fmi y de la Comisión Europea, los gobiernos europeos se inclinaron por la segunda estrategia implementando, desde 2010 para algunos y 2011 para todos, políticas de austeridad o de rigor fuertemente restrictivas que dañarán el crecimiento. Así cuando la fragilidad de la reactivación debió haber conducido a proseguir estrategias presupuestales de reactivación, varios países europeos (Inglaterra, Italia, Alemania, Francia, España, Grecia, Portugal, Irlanda, Dinamarca y Rumanía) bajo la presión de los mercados financieros, emprendieron en la primavera 2010 un viraje hacia el rigor para reestablecer el equilibrio de las finanzas públicas. En efecto, se comenzaron a aplicar programas de austeridad sin precedente en Europa como los que conoció América Latina en los años ochenta y que condujeron a "la década pérdida”. Dichos programas, que olvidan que en la historia económica reciente no existe un solo país que habiendo aplicado el rigor presupuestal haya generado un aumento de crecimiento (Creel, 2010: 33) condenan a los países europeos a un retroceso de actividad en el corto plazo y a un largo periodo de recesión. Pretender disminuir los déficits públicos por debajo de 3\% y acercar la deuda pública al nivel mítico de $60 \%$ en un plazo de 3 a 5 ańos constituye una auténtica trampa suicida. El gran peligro actual es que los países europeos quieren todos reducir la deuda al mismo tiempo demasiado rápido. ${ }^{23}$ Así, tras haber improvisado planes keynesianos de reactivación e incluso haber nacionalizado temporalmente bancos para enfrentar la crisis de los subprimes (suspendiendo provisionalmente en los hechos el Pacto de Estabilidad y Crecimiento esperando días mejores), ${ }^{24}$ los poderes públicos europeos quieren cerrar lo más

23 Después de la Segunda Guerra Mundial la deuda de los Estados Unidos representaba 250\% del PIB, pero tardaron casi 15 años para reducirla. La cuestión del reembolso de la deuda y de su carga se planteó con una amplitud inédita en la historia. Para disminuir la relación entre el endeudamiento y el ingreso nacional se puede elegir entre aumentar el ingreso nacional o reducir el endeudamiento. La mala respuesta es preconizar una reducción absoluta de la deuda. Domar, por el contrario, preconizó para los Estados Unidos un ingreso nacional en expansión y eso es lo que aconteció: el crecimiento americano de la posguerra disminuyó el endeudamiento gracias al aumento del ingreso nacional (Domar, 1944).

24 Con la excepción de Dinamarca, Estonia, Luxemburgo y Suecia, ninguno de los 27 miembros de la Unión Europea logró respetar el umbral del 3\% del рів fijado por el Tratado de Maastricht, algunos de los países más frágiles como Grecia, España e Irlanda alcanzando incluso déficits superiores a $10 \%$. Como consecuencia de la degradación del saldo presupuestal, en 2009 de los 16 países que cuenta la zona euro, sólo 6 (España, Chipre, Luxemburgo, Eslovenia, Eslovaquia, Finlandia) tuvieron una relación deuda pública/PIB inferior a $60 \%$ (Antonin, 2010: 16-17). 
rápido posible este paréntesis. El cambio súbito de las políticas económicas europeas pasando de la reactivación a la austeridad muestra muy claramente el olvido de los imperativos económicos y sociales para sostener la actividad interna a favor de una intromisión externa para mantener el valor de los títulos soberanos. Lo anterior demuestra la anomalía política sin precedente en una sociedad supuestamente democrática: la subordinación de las políticas públicas a una comunidad externa que no forma parte del contrato social. Los mercados financieros, lejos de ser simples intermediarios neutrales entre ahorradores y prestatarios o un puro instrumento de inversión de las empresas y de gestión de los riesgos, ejercen de hecho una influencia política importante, lo que constituye un peligro para la democracia. En tanto que los dirigentes políticos aunque sean incompetentes o desagradables representan la elección de los ciudadanos, los inversionistas no son elegidos ni responsables políticamente ante nadie. Si la voluntad de la mayoría, puede ser cuestionada por el poder económico de una minoría anónima que actúa a través de los mercados financieros la democracia se pone en peligro. En estas condiciones, un proceso acumulativo perverso se desencadena: frente a una depresión que hace aparecer un déficit, el Estado reacciona con una baja de gastos y/o un alza de impuestos tratando de desaparecer el déficit. Sin embargo, es probable que de ello resulte una compresión aún más fuerte del ingreso global, lo que hará bajar aún más los impuestos. A este resurgimiento del déficit, el Estado responderá con mayores recortes de gastos y/o tasas más elevadas de imposición o nuevos impuestos, etcétera (Parguez, 2002: 5).

Como vemos las deudas privadas que en un primer momento fueron absorbidas por las finanzas públicas trasformándose en deudas soberanas ahora se transfieren, mediando la presión de los mercados financieros, a los pueblos europeos a través de drásticos planes de austeridad. El neoliberalismo Hayekiano regresa con fuerza a pesar de su fracaso patente en otras latitudes como en América Latina en los ochenta.

Los resultados no se hicieron esperar y en el otońo de 2010 la crisis se extiende a Irlanda, hasta hace poco tiempo ejemplo de flexibilidad neoliberal exitosa, este país se encontró en el centro de la tormenta europea. Con el desplome del "milagro irlandés", ${ }^{25}$ donde el Estado se vio obligado a volverse el garante

25 Irlanda debe su espectacular despegue de la década 1990 no sólo a las ayudas europeas sino sobre todo a un dumping fiscal no coordinado con el resto de Europa. La tasa de imposición de las sociedades fijada en $12.5 \%$ corresponde a menos de la mitad de la tasa media aplicada hoy en la Unión (Padis, 2010: 80). 
de un sistema bancario volatilizado por sus excesos, ${ }^{26}$ se abre un nuevo ciclo de sobre reacción de los mercados que podría extenderse a Portugal, España e Italia. A finales de noviembre del 2010, la Unión Europea con el apoyo del FMI implementa un plan de ayuda a Irlanda y le da un plazo suplementario de un ańo para reducir su déficit de 32\% del pib en 2010 a menos de $3 \%$ del PIB en 2015 (con la autorización de mantener sin cambio la tasa impositiva sobre las sociedades a 12.5\%) (Proutat: 2011: 5). Como resultado de la crisis irlandesa se crea el Mecanismo Europeo de resolución de crisis que va a sustituir al Fondo de Estabilización que tiene una duración temporal. El mecanismo de Estabilización introduce dos novedades. En primer lugar, perenniza la asistencia financiera mutua en el seno de la Unión. En segundo lugar, asocia al sector privado, permitiendo que las obligaciones emitidas por los Estados de la Unión contemplen cláusulas de acción colectiva. Dichas cláusulas autorizarán que un país cuya deuda pública entre en una trayectoria insostenible tenga la posibilidad de renegociar los términos de la deuda con una mayoría de los acreedores.

\section{HAYEK VERSUS KEYNES}

Precios y producción de Hayek (1931) es uno de los libros de economía más importantes entre los escritos en el siglo xx. ${ }^{27}$ En él, el economista austriaco naturalizado inglés, rompe con el enfoque cuantitativo de la teoría monetaria tradicional. Demuestra que la moneda no es neutra, que lejos de ser un velo, está en el corazón de los fenómenos económicos (producción, precios relativos, crisis ...). Para Hayek, la moneda ejerce siempre una influencia determinante en el curso de los fenómenos económicos y cualquier análisis será incompleto si se deja de lado el papel de la moneda.

Hayek pone el acento en los fenómenos de estructura al atribuir a la moneda una acción sobre los precios relativos más allá de su influencia sobre el nivel

26 La crisis irlandesa obedece a una lógica muy diferente a la de la griega ya que se trata de una prolongación de la crisis de la esfera financiera privada: el descubrimiento de una situación de los bancos aún más frágil que lo que se imaginaban provocó un movimiento de desconfianza en cuanto a la calidad de los depósitos bancarios (Mistral, 2010: 104).

27 En la obra de Hayek se distinguen dos periodos: el primero que va de 1928 a 1941, en el que publica obras meramente económicas, y el segundo que abarca de 1944 hasta su muerte en 1992, en el que su producción es sobre todo de obras de filosofía económica y política. Entre estos últimos cabe destacar The Road of Serfdom (1944) y los tres volúmenes reunidos bajo el título de Law, Legislation and Liberty $(1973,1976,1979)$. 
medio de los precios. En este sentido su análisis es más profundo que los estudios puramente globales con respecto a los cuales manifiesta una cierta desconfianza. Para Hayek cualquier intento por descubrir una medida estadística bajo la forma de un promedio general del volumen total de producción, de comercio o de la actividad general de los negocios sólo llevará a esconder los fenómenos realmente significativos como los cambios en la estructura de la producción.

Las conferencias de Hayek en la London School of Economics and Political Science y el libro a que dio origen tuvieron un eco importante. La severa crítica de Sraffa (1932), el análisis de Precios y Producción de Hawtrey (1932) y el artículo de Kaldor (1942) muestran que los grandes economistas de esa época percibieron la importancia de la obra. Tal no fue el caso de Keynes quien afirmó que precios y producción "la más horrible mezcla que haya leído» y «un ejemplo extraordinario de la manera en que partiendo de un error un implacable lógico puede caer en un asilo de locos» (1931).

La reacción de Hayek a este ataque de Keynes tardó en venir. En 1936, cuando aparece la Teoría General, Hayek rechaza hacer la crítica. «Fue el más grande error de mi vida» comentará posteriormente (cit. en Lepage, 1980: 419). Sin embargo, en 1975 cuando aparece la edición francesa de su libro Precios y producción no deja pasar la ocasión para expresar su opinión sobre Keynes. A este respecto señala en el prefacio que Keynes teoriza una práctica que conviene perfectamente a los políticos que preocupados por la proximidad de las elecciones manipulan un instrumento barato (los gastos públicos) cuya influencia es rápida para bajar el desempleo a un precio que se pagará sólo en un futuro lejano. Su desprecio por la teoría del maestro de Cambridge se confirma a finales de los ochenta. En una de sus principales obras de esta época Hayek afirma que "Keynes se opuso... a la tradición moral que reconoce la virtud del ahorro, y rechazó, como miles de economistas poco serios, reconocer que una reducción de la demanda de bienes de consumo es generalmente requerida para permitir un crecimiento de la producción de bienes de producción... lo que lo condujo a dedicar sus formidables capacidades intelectuales a elaborar una 'teoría general' de la economía a la cual le debemos la inflación que ha reinado planetariamente durante tres cuartos de este siglo" (1988: 80). Además, según Hayek, Keynes "justifica... ciertas de sus concepciones económicas y su creencia general en una organización centralizada del orden de mercado escribiendo que 'en el largo plazo todos estaremos muertos' (lo que quiere decir que poco importan los daños a largo plazo que podamos cometer, lo único que cuenta es el momento presente, el corto plazo, con todo lo que comporta de sumisión a la opinión pública, de seducción del electorado, de corrupción y de demagogia" (1988: 80). Tras afirmar lo anterior, Hayek finaliza sus comentarios negativos sobre el maestro de 
Cambridge señalando que "Keynes no sólo conocía mal la filosofía sino también la economía” (1988: 80).

Sin entrar a analizar de manera detallada la opinión de Hayek sobre Keynes, no está por demás hacer un breve comentario de la célebre frase de Keynes "en el largo plazo todos estaremos muertos", ya que ello es revelador sobre la actitud poco seria de Hayek. En efecto, esta frase aparece en el libro publicado por Keynes en 1923: A Tract on Monetary Reform (traducido en Francia en 1924). Pero en ese caso se trata simplemente de subrayar que si la teoría cuantitativa de la moneda podría tener alguna validez es sólo en el largo plazo, por lo que no es de ninguna ayuda para comprender la evolución de la coyuntura inmediata. Es un auténtico abuso deducir como lo hace Hayek un juicio filosófico general sobre la despreocupación de Keynes con respecto al futuro.

Muchos de los juicios emitidos por Hayek contra Keynes, los podemos comprender como parte del combate intelectual del más connotado economista neoliberal del siglo xx. Los compromisos filosóficos y políticos de Hayek como miembro eminente de la Sociedad del Mont-Pèlerin lo llevan a sostener tesis extremas. Es justamente esta visión de todo o nada la que vuelve el análisis de Hayek poco convincente. La elección, evidentemente, no es entre el orden espontáneo del mercado y el totalitarismo, sino entre grados diferentes de intervención. La realidad es que actualmente todas las economías capitalistas son economías mixtas. ${ }^{28} \mathrm{La}$ elección de un cierto nivel de intervencionismo no ha llevado ineluctablemente al totalitarismo. Hay una gran exageración en esta visión de un orden que si no es puro lleva inevitablemente al "infierno socialista”. Pero hay sobre todo un olvido fundamental: el mercado quizás sea un buen regulador local pero evidentemente es un mal regulador global.

De cualquier manera, el análisis Hayekiano de la igualdad ex ante entre el ahorro y la inversión, basado en un supuesto irrealista de ocupación plena, ha servido para justificar las políticas de austeridad con los efectos devastadores que conocemos.

\section{Hayek en Europa}

Las políticas de rigor que se aplicaron en México tras el estallido de la crisis de la deuda (Guillén Romo, 1990) y que ahora se están aplicando en Europa se

28 Incluso los Estados Unidos están lejos de ser una economía de "libre mercado" con un sector Estatal subdesarrollado o encogido. Se trata más bien de un país avanzado como los otros en los que el sector público asegura más de la mitad de la actividad económica (Galbraith, 2009: 167). 
inspiran en la teoría del capital de Hayek (Guillén Romo, 2000), autor que hizo un gran esfuerzo por darle apariencia científica al adagio "hay que vivir según nuestros medios".

La teoría de Hayek es una de las expresiones más acabadas del mundo clásico (y neoclásico) donde la sociedad dispone de un fondo para gastar en inversión antes de que haya decidido invertir. Para formar este fondo (ahorro) basta con disminuir el consumo presente. Desde esta perspectiva, el ahorro determina la inversión y la política de rigor es benéfica, ya que incrementa el fondo de ahorro que se destina a la inversión (Parguez, 1984). No cabe la menor duda de que los economistas y políticos que propugnan y aplican actualmente en Europa la política de rigor son consciente o inconscientemente esclavos del modelo hayekiano, como lo fueron los economistas y políticos que aplicaron las políticas de austeridad en América Latina en los ochenta.

Como lo ha señalado la corriente keynesiana francesa, particularmente Alain Parguez (Bliek y Parguez, 2006), la doctrina del rigor dispone de una serie de principios o mandamientos, de una explicación de la crisis y de una estrategia para superarla.

Los tres mandamientos fundamentales son los siguientes: 1) La sociedad debe converger hacia el sendero del rigor. Todos los agentes deben saldar sus cuentas sin recurrir al crédito. Todos deben vivir según sus verdaderos medios. Deben vivir en la realidad; 2) Para converger hacia el estado de rigor, la sociedad debe abolir los falsos medios de gasto que nutren los déficits en las cuentas; 3) Para equilibrar las cuentas la sociedad debe sufrir una reducción de su nivel de vida. Mientras más se empobrezca hoy aceptando "el sacrificio necesario", más gozará mañana de verdaderas riquezas.

De estos tres mandamientos se deduce sin dificultad la explicación de la crisis: ésta resulta de una acumulación de déficits en las cuentas. Gracias al crédito los Estados, las empresas y las familias pudieron gastar más de lo que ganaban. La sociedad invirtió por encima de lo que permitía su fondo de ahorro. El orden desapareció en la sociedad, que se alejó cada vez más del sendero de rigor. Los déficits causaron la inflación que a su vez provocó el desempleo, etcétera.

La estrategia para superar la crisis sería:

Bloquear el recurso a la moneda impidiendo que la moneda salga de su humilde papel de medio de cambio.

Reducir el desequilibrio en las cuentas: 1) Reducir el déficit del sector público gracias a una reducción del gasto público y a un aumento de los impuestos a las familias. El Estado de preferencia deberá tener un presupuesto equilibrado sin déficit presupuestal, sin recurrir a préstamos y sin creación monetaria. 2) Reducir el déficit acumulado de las empresas. Las empresas deben equilibrar 
sus cuentas. No deben financiar sus gastos con crédito. Deben autofinanciarse gracias a su beneficio lo que las obliga a comprimir los salarios y el empleo. 3) Reducir el déficit de las familias obligándolas a reembolsar su deuda contratada para consumo y a consumir en función de sus medios. En la medida de lo posible incitarlas a ahorrar y a no comprar a crédito: el equilibrio de las cuentas significa no vivir por encima de sus medios, es decir, a crédito.

Todos los grandes equilibrios deben ser respetados. El endeudamiento exterior debe ser prohibido.

La realización de todos estos equilibrios conduce a una reducción del consumo. El equilibrio presupuestal reduce el ingreso de las familias. Esta baja del consumo reduce las importaciones permitiendo el reequilibrio de la balanza comercial. Los salarios se ven sometidos a una presión tanto más convincente que la tasa de desempleo es elevada. La finalidad del control de los salarios es aumentar la capacidad de autofinanciamiento de las empresas.

En general se trata de imponer una cura general de austeridad: mientras más se limiten los agentes económicos hoy, se enriquecerán más en el largo plazo aunque sin tener la certidumbre del momento en que los frutos del crecimiento estarán suficientemente maduros para consumirlos.

Esta doctrina de la austeridad que recomienda el rigor para las economías europeas, sobre todo la griega y la española cuyos agentes económicos se habrían comportado como las cigarras de la fábula de Jean de La Fontaine, es válida en una economía aun dominada por la agricultura como la estudiada por Adam Smith y David Ricardo (Bliek y Parguez, 2006: 45-50; Bousseyrol, 2009: $117-$ 118). En dicha economía, el stock de trigo que no es pagado como salario a los obreros agrícolas podrá ser utilizado como semilla en el futuro. El ahorro en trigo es entonces la inversión en trigo. Mientras más bajos sean los salarios pagados en trigo hoy mayor será el ahorro realizado en trigo, garantizándole a la sociedad agrícola un enriquecimiento en el futuro. La frugalidad se vuelve así la condición necesaria y suficiente para el crecimiento. El ahorro es la inversión, determina la inversión. En este cuadro campestre, si el reinado pretende extraer una parte del trigo para mantener su administración y garantizar su soberanía la riqueza futura se verá comprometida. En estas condiciones correspondientes al Antiguo Régimen, la teoría del ahorro previo es completamente válida. Pero cuando la sociedad industrial paga a sus obreros con moneda, asegura el desarrollo de su aparato productivo gracias al crédito bancario, la transposición al mundo moderno de la teoría agrícola del ahorro plantea muchos problemas. Así, por ejemplo (Bliek y Parguez, 2006: 55), en las economías monetarias, si se extrapolan comportamientos individuales a nivel colectivo, se está negando la realidad. Si un individuo reduce su consumo para ahorrar puede financiar 
sus propias inversiones. Pero si se extiende el razonamiento a la colectividad se llega a un contrasentido manifiesto: los créditos y las deudas se anulan porque todo crédito es la contrapartida de una deuda. Un aumento de ahorro privado origina un menor ingreso para las empresas. Luego entonces, extraer liquidez disminuyendo el consumo disminuye el ingreso global. Se modifica la distribución entre las tesorerías individuales pero a nivel social no hay un mayor fondo destinado a la inversión.

\section{LA INEPCIA DE LA DEUDA PÚBLICA COMO CARGA Y SÍMBOLO DE DESORDEN SOCIAL}

Las políticas de austeridad aplicadas en varios países latinoamericanos en los ańos ochenta y que ahora se están volviendo a aplicar en Europa ven a la deuda pública como una carga y un símbolo de desorden social (Bliek y Parguez, 2006: 64-79; Bousseyrol, 2009: 19-46). Las declaraciones oficiales ayer en América Latina y hoy en Europa ponen el acento sobre el carácter catastrófico del endeudamiento. Ésta sería la causa de la impotencia del Estado que carecería de medios financieros para actuar. Sería también la revelación de una falta política y moral: los países vivirían por encima de sus medios. El endeudamiento contribuiría al deterioro de las condiciones financieras nacionales.

La tesis de la carga de la deuda pública no es nueva. Se trata de un viejo argumento que constituye el arma principal de los teóricos que justifican la impotencia del Estado. Ya en 1803, Jean-Baptiste Say señalaba que "una nación como un particular sólo podrán liberarse de una deuda y de las obligaciones que impone gracias a la superioridad que llega a mantener entre sus ingresos por encima de sus gastos; la deuda se reembolsa en la medida en que los ingresos superen a los gastos" (Say, 1840: 465). El paralelismo entre la nación y el particular está bien caracterizado en Say. Un particular sólo puede pagar su deuda reduciendo sus gastos con respecto a sus ingresos. Lo mismo le acontece a la nación: debe extraer un excedente presupuestal. Los ingresos de los particulares son similares a los ingresos de una nación. Como si los ingresos fiscales pudieran asimilarse a un ingreso fijo independiente de la coyuntura y del impacto del gasto público sobre el ingreso nacional. Así, Say aporta una de las primeras cauciones científicas a la crítica política de la deuda estableciendo una analogía entre el gasto público de la nación y el gasto privado de los particulares.

En el siglo xx la percepción política de la deuda se radicaliza. Dos guerras mundiales con costos sociales exhorbitantes confortan la idea de que no hay que sobrecargar el costo de la reconstrucción con gasto público inmoderado. 
Finanzas sanas y moneda fuerte son las dos condiciones necesarias para un país que sale de la guerra. Jacques Rueff, el más grande exponente de la escuela neoliberal francesa, continuará en la línea de Say tratando de darle un fundamento científico al adagio "hay que vivir según sus medios". En efecto, en su teoría del Orden Social Rueff (1967) subraya los daños del déficit. Para él, la deuda es la contrapartida del déficit presupuestal. Los gastos excesivos no cubiertos por el impuesto desembocan en la emisión de bonos del Tesoro y obligaciones. Este aumento de recursos generaría un excedente de moneda no deseado por los consumidores. La moneda crearía derechos sobre la producción. Genera "falsos derechos" ya que, según Rueff, la oferta no sigue la demanda. La moneda se volvería "la alcantarilla colectora de falsos derechos". A finales de los cincuenta como consejero del General de Gaulle, Rueff preconiza que el presupuesto del Estado sea presentado en forma unificada respondiendo al imperativo del equilibrio. Los gastos corrientes del Estado deben financiarse con los impuestos y los gastos no corrientes como la inversión deben ser financiados con el ahorro. La inflación provendría del hecho de que los gastos del Estado no son cubiertos ni por el impuesto ni por el ahorro. Para Rueff un presupuesto deficitario conduciría a una propagación de la inflación, reduciendo las tasas de interés reales, lo que desalentaría el ahorro de los individuos. Lo que quiere decir que si la coyuntura económica es mala, el gobierno debe impedir la acción de los estabilizadores automáticos. Si una recesión reduce el rendimiento de los impuestos, se necesita entonces, según Rueff, reducir los gastos del Estado o aumentar los impuestos. La consecuencia de esta conducta será la agravación de la recesión disminuyendo aún más la demanda agregada.

Como vemos, Rueff converge totalmente con Hayek en la idea de que el ahorro es una especie de fondo donde el Estado podría alimentarse. Sin embargo, compitiendo con el Estado, los inversionistas privados correrían el riesgo de no poderse financiar. La inversión se considera como financiada exclusivamente con el ahorro. El ahorro, incluyendo los beneficios, es para los dos autores más importante que el consumo. Finalmente para ellos, los beneficios varían inversamente al consumo. Su análisis excluye el crédito para financiar el consumo y el papel de la moneda en la economía.

La idea de que el Estado y los organismos sociales ajusten sus gastos a los ingresos de tal suerte que no haya nunca déficit dominó la literatura económica como un auténtico artículo de fe. En estas condiciones, expertos y políticos de derecha, y en muchos casos de izquierda, se pusieron a recitar los dogmas neoliberales. Así, por ejemplo, después de la Segunda Guerra Mundial, el gobernador del Banco de Francia y el Libro Blanco británico del 10 de marzo de 1952 constataban en los mismos términos que Francia e Inglaterra "vivían por 
encima de sus medios" debido a sus déficits (Bliek y Parguez, 2006: 65). En el mismo sentido se expresaba, con una claridad meridiana digna de Benjamin Frankling ${ }^{29}$ el presidente de México en plena crisis de la deuda latinoamericana de inicios de los ochenta:

"Estamos en crisis como nación y como comunidad porque hemos descuidado los equilibrios económicos fundamentales. Hemos descuidado el equilibrio necesario entre lo que consumimos y lo que ahorramos, hemos consumido más de lo que hemos ganado con nuestro trabajo. Por eso tenemos una deuda alta (...) Necesitamos invertir más, ahorrar más y para ello tenemos que limitar el consumo" (De la Madrid, cit. Guillén Romo, 1985: 86).

Resulta curioso que siempre haya habido una mayor preocupación por los déficits públicos que por los déficits privados (Généreux, 2002: 146-148). Esto proviene en parte de que no se ha tomado conciencia de la amplitud de estos últimos. Ahora bien, no hay que olvidar que a nivel macroeconómico el sector de las empresas vive permanentemente por encima de sus medios por la simple y buena razón de que realiza lo esencial de las inversiones en tanto que el ahorro está en posesión de las familias: luego entonces es global y estructuralmente deficitario y prestatario.

Por otro lado, cabe señalar una diferencia fundamental entre la contabilidad privada y la contabilidad pública. En las cuentas de una empresa no se registran los gastos de inversión como cargas para el ejercicio corriente ya que la maquinaria y el equipo contribuirán a la producción durante numerosos años. Cada año en la línea de amortización sólo se imputará en las cargas corrientes una fracción de los gastos de inversión. Desgraciadamente, este tratamiento lógico no es posible cuando se establece el presupuesto del Estado y de otras colectividades públicas. En efecto, las reglas de la contabilidad pública exigen que se registren en el presupuesto todos los gastos del año votados por las asambleas competentes, tanto los gastos corrientes como los gastos de inversión. Por esta simple razón contable, un presupuesto puede presentar un déficit provocado por las inversiones, aunque los ingresos corrientes cubran o superen los gastos corrientes. En este último caso, respetando la lógica económica se debería considerar que el presupuesto está equilibrado o que presenta un excedente. El equilibrio a mediano plazo del saldo corriente del presupuesto público debería ser un objetivo

29 La exaltación del ahorro que se desarrolla bajo la influencia del protestantismo se vuelve a encontrar bajo la pluma de Benjamin Frankling, quien señala al respecto que "un hombre puede si no sabe ahorrar lo mismo que ganar, estar con la nariz pegada al trabajo toda su vida y morir sin un penique" (Frankling, 1983). 
pertinente. En periodo de débil coyuntura, se debería permitir que los gastos corrientes superen a los ingresos corrientes recurriendo al endeudamiento, con la condición de que en la fase de auge el excedente de ingresos corrientes permita reembolsar las deudas contratadas. Además, en materia de inversión se debería permitir que se aplique a la contabilidad pública el mismo razonamiento que se aplica a la contabilidad empresarial. El déficit y el endeudamiento se justifican cuando financian bienes y equipos públicos indispensables (carreteras, universidades, hospitales, etcétera) cuyo efecto positivo sobre el crecimiento generará ingresos fiscales que permitirán reembolsar los créditos contratados. Claro está que, como en el caso de la empresa privada, existen buenas razones para preocuparse de los déficits, si éstos no generan a plazo la capacidad de reembolso necesaria y obligan a un perpetuo endeudamiento creciente (efecto de bola de nieve). En este último caso, el déficit excesivo genera una carga de deuda creciente que amputa los recursos disponibles para los bienes públicos y redistribuye el dinero de los contribuyentes hacia los detentores de capital financiero (rentistas).

De cualquier manera, la teoría que considera la deuda como una carga en cualquier circunstancia reposa como lo demostró Evsey Domar (Domar, 1944) en dos postulados erróneos, más ideológicos que científicos: 1) El primero consiste en pensar que los gastos del Estado son por naturaleza improductivos o en el mejor de los casos que tendrán un efecto nulo sobre el crecimiento o incluso un impacto negativo; 2) El segundo postulado considera que la tasa de interés es impuesta al Estado por los mercados financieros. Apoyándose en el efecto de desplazamiento se considera que mientras más importante sea el déficit, más extraerá ahorro el Estado y más aumentará la tasa de interés.

Domar considera que el aumento del gasto público contribuye al crecimiento de la demanda global y, por lo tanto, del ingreso. Inversamente, los impuestos actúan de manera opuesta. El déficit del Estado aumentando el gasto público favorece el ingreso global suscitando un aumento del crecimiento económico. En la medida en que la tasa de interés media pagada por la deuda es inferior a la tasa de crecimiento, la carga de la deuda pesará cada vez menos. La relación de la deuda sobre ingreso nacional se estabilizará o disminuirá.

Según Domar, la política monetaria tiene por función fijar la tasa de interés por debajo de la tasa de crecimiento de la economía. Esto es posible, ya que la tasa de interés depende de las autoridades monetarias más que de los mercados financieros. En efecto, como lo ha demostrado la corriente poskeynesiana anglosajona y la teoría francesa del circuito (Piégay y Rochon, 2006), la cantidad de moneda en circulación está determinada por el gasto de los agentes. Depende de la creación monetaria de los bancos que otorgan créditos. La moneda no cae del cielo lanzada por un helicóptero como lo había imaginado Friedman, el helicóptero 
siendo una banca central independiente. Las demandas de préstamos de las empresas y las familias explican la creación monetaria. La coyuntura del mercado fija la necesidad de crédito. Al contrario, lo que depende de las autoridades monetarias es la capacidad de fijar la tasa de interés a corto plazo. Lo que quiere decir que la tasa de interés es autónoma con respecto a las fuerzas del mercado. La tasa de interés no es un precio que iguala la oferta y la demanda de préstamos. Los bancos otorgan crédito al precio del mercado monetario recargado de un porcentaje con un cierto racionamiento.

En estas condiciones existe un margen de maniobra para las autoridades monetarias. En Estados Unidos, por ejemplo, las tasas de interés a largo plazo determinadas por el mercado dependen de las tasas de interés a corto plazo determinadas por la FED. Todo converge hacia la idea de que si el Estado no renuncia a su soberanía monetaria como en Europa, pagará la tasa de interés que decida sobre la deuda pública. El margen de maniobra para fijar la tasa de interés permite disminuir la carga de la deuda. Desgraciadamente, dicha carga esta aumentando en Europa en virtud de la reducción cada vez más fuerte del PIB provocada por las políticas cada vez más brutales de deflación que se generalizaron tras la crisis griega.

\section{CONCLUSIÓN}

La moneda común presupone una fuerte integración comercial, un nivel elevado de especialización productiva, una gran movilidad de los factores de producción, una gran flexibilidad de precios y salarios, mecanismos de transferencia presupuestales significativos, una simultaneidad de los ciclos económicos y preferencias comunes. Aunque Europa no satisfacía todos los criterios establecidos por la teoría económica, particularmente la alta movilidad de mano de obra y mecanismos de transferencia presupuestales significativos, la construcción monetaria europea bajo una orientación neoliberal se puso en marcha a principios de los noventa. En tiempos de tranquilidad económica la Unión Económica y Monetaria funcionó aunque la zona euro no fuera óptima desde el punto de su coherencia interna. El BCE, gracias a una fuerte independencia, y el PEC, mediante reglas estrictas en materia de finanzas públicas, permitieron borrar superficialmente la heterogeneidad de las estructuras económicas, políticas y sociales. Pero cuando la crisis llegó, las restricciones que pesan sobre la Unión se endurecieron y las contradicciones se manifestaron. Los Estados de la zona euro abandonaron sus poderes monetarios pero no fueron capaces de dar el segundo paso transfiriendo una parte de sus poderes presupuestales. 
La crisis financiera internacional que sacudió al mundo en 2007 y 2008, contra lo que podría haberse esperado, no parece haber debilitado el dominio de los esquemas de pensamiento neoliberal que orientan las políticas económicas desde hace treinta años. A pesar de las múltiples promesas en las cumbres del G8 y del G20 el poder de la finanza no ha sido cuestionado en sus fundamentos. Muy por el contrario, en Europa, los Estados bajo la presión de Bruselas, del FMI, de las Agencias de Notación y de los mercados financieros, supuestamente eficientes, aplican con un renovado vigor programas neoliberales de reformas y ajuste estructural que en América Latina durante los ochenta condujeron a "la década pérdida" caracterizada por un aumento de la inestabilidad y de las desigualdades. Las políticas de austeridad que ahora se están volviendo a aplicar en Europa, ignorando el mensaje keynesiano, ven al Estado como un parásito o "como un padre de familia alcohólico que bebió por encima de sus medios". Dichas políticas imponen a la sociedad una serie de medidas de austeridad, de privatización de los servicios públicos y de flexibilización del mercado de trabajo que sacrifican el crecimiento, impulsan el desempleo, aumentan la pobreza y el rechazo social como se observó recientemente, sobre todo en Grecia e Irlanda. La aplicación de dichas políticas manifiesta una situación de extrema dependencia de los mercados de capitales, de sometimiento de las políticas públicas a las exigencias de un grupo de acreedores internacionales poseedores de la deuda soberana de los Estados Europeos y lo que es peor una alineación de las soberanías democráticas. Se está viviendo una anomalía política sin precedente en una sociedad supuestamente democrática: la subordinación de las políticas públicas a una comunidad externa que no forma parte del contrato social. Los mercados financieros, lejos de ser simples intermediarios neutrales entre ahorradores y prestatarios o un puro instrumento de inversión de las empresas y de gestión de riesgos, ejercen de hecho una influencia política importante, lo que constituye un peligro para la democracia. Los dirigentes políticos pueden ser incompetentes o desagradables pero representan la elección de los ciudadanos. No es el caso de los inversionistas que no son elegidos ni responsables políticamente ante nadie. Cuando la voluntad de la mayoría, puede ser cuestionada por el poder económico de una minoría anónima que actúa a través de los mercados financieros la democracia se pone en peligro.

\section{BIBLIOGRAFÍA}

Antonin, C., "La Grèce: cas particulier ou crise générale de l'endettement Public?”, Cahiers Français, Nº 359, La Documentation Française, 2010. 
Askenazy, P., T. Coutrot, A. Orléan y H. Sterdyniak, Manifeste d'économistes atterrés. Crise et dette en Europe: 10 fausses évidences, 22 mesures en débat pour sortir de l'impasse, Villeneuve-d'Ascq, Les liens qui libèrent, 2010

Bénassy-Quéré, A. y L. Boone, "Crise de l'eurozone: dettes, institutions et croissance”, La Lettre du CEPII, N³00, 2010.

Bliek, J. y A. Parguez, Le Plein Emploi ou le Chaos, Paris, Economica, 2006.

Bousseyrol, M., Vive la dette!, Paris, Editions Thierry Magnier, 2009.

Creel, J., "Les politiques budgétaires: de la relance à la rigueur", Cahiers Français $\mathrm{N}^{\circ}$ 359, La Documentation Française, 2010.

Couderc, N. y O. Montel-Dumont, "Des subprime à la crise mondiale", Cahiers Français, № 359, La Documentation Française, 2010.

D'Arvisenet, P., "Crise de la dette souveraine en Europe", Conjoncture, BNP PARIBAS, enero, 2011.

Dévoluy, Michel, "L' Euro et le PSC dans la tourmente", Cahiers Français N ${ }^{\circ}$ 359, La Documentation Française, 2010.

Domar, E. D., "The 'burden of the debt' and the national income", The American Economic Review, vol. 34, num. 4.

Eichengreen, B., "Coûts et avantages de l'unification monétaire de l'Europe" en Vers l'union économique et monétaire européenne, Ministère de l'Economie et des Finances, La Documentation Française, 1990,

Frankling, B., Autobiografía y otros escritos, México, Porrúa, 1983.

Friedman, M., y R. Friedman, Capitalisme et Liberté, Paris, Robert Laffont, 1971.

Galbraith, J. K., L'Etat Prédateur, Paris, Seuil, 2009.

Généreux, J., Introduction à la politique économique, Paris, Seuil, 1999. , Les vraies lois de l'économie, Paris, Seuil, 2002.

Guillén Romo, H., El sexenio de crecimiento cero, México, 1982-1988, México, ERA, 1990.

, "Hayek y la austeridad en México", Cuadernos Políticos, núm. 44, 1985.

,"La teoría de la sobreinversión de Hayek", Comercio Exterior, 2000.

Hayek, F., La présomption fatale, Paris, Presses Universitaires de France, 1988. , Law, Legislation and Liberty: A New Statement of the Liberal Principles of Justice and Political Economy, vol I, Rules and Orden, Londres, Routledge and Kegan Paul, 1973.

, Law, Legislation and Liberty, vol. II, The Mirage of Social Justice, Londres, Routledge and Kegan Paul, 1976.

, Law, Legislation and Liberty, vol. III, The Political Order of a Free People, Londres, Routledge and Kegan Paul, 1979. 
Hayek, F., Prices and Production, Londres, Routledge \& Sons, 1931. , The Contitution of Liberty, Londres, Routledge and Kegan Paul, 1960. , The Road to Serfdom, Londres, Routledge \& Sons, 1944.

Hawtrey, R. G., "Recension de Prices and Production", Economica, vol 12, num. 35, 1932.

Kaldor, N., "Professor Hayek and the Concertina Effect", Economica, vol 9, num. 36, 1942.

Kauffmann, P., L'euro, Paris, Dunod, 1997.

Keynes J. M., La réforme monétaire, Paris, Payot, 1924.

Keynes, J. M., The General Theory of Employment, Interest and Money, Londres, Mac Millan, 1936.

Keynes, J. M., "The Pure Theory of Money. A Reply to Dr. Hayek”, Economica, noviembre, 1931.

Lepage, H., Demain le liberalisme, Paris, Pluriel, 1980.

Mistral, J., "Des dettes privées aux dettes publiques: quelle est la prochaine étape de la crise?", Esprit, Diciembre, 2010.

Mundell, R., "A Theory of Optimum Currency Areas", American Economic Review, vol. 51, 1961.

Padis, M. O., "De 2008 à 2010, l'euro, les banques et les choix budgétaires", Esprit, Diciembre, 2010.

Parguez, A., "La dynamique de la monnaie", Economies et sociétés, XVIII, núm, 4, 1984.

Parguez Alain, "Le Modèle Européen de l'Union Monétaire: L'harmonisation par l'austérité" Journée d'études du Centre d'Etudes de la Pensée et les Systèmes Economiques, Grenoble, 2002.

Piégay, P. y Rochon, L. P., Teorias monetarias poskeynesianas, Madrid, Akal, 2006.

Proutat, J. L., "L'Uem prieé de serrer les rangs", Conjoncture, BNP PARIBAS, enero, 2011, Reinhart, C. M y K. S. Rogoff, Cette fois, c'est différent huit siècles de folie financière, Paris, Pearson, 2010.

Rueff, J., "Un instrument d'analyse économique: la théorie des vrais et des faux droits", en Les fondements philosophiques des systèmes économiques. Textes de Jacques Rueff et essais rédigés en son honneur, Paris, Payot, 1967.

Say Jean-Baptiste, Cours complet déconomie politique, 2è édition II, 1840.

Sraffa, P., "Dr. Hayek on Money and Capital", The Economic Journal, marzo, 1932.

Sterdyniak, H., "L'endettement des Etats et des particuliers: une menace pour la stabilité de l'économie?", Cahiers Français, núm, 357, 2010.

Wallace, L., "Robert Mundell, un économiste en avance sur son temps", Finances et Développement, septiembre, 2007. 